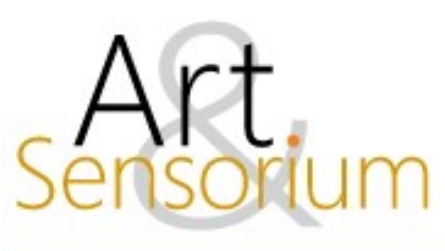

\title{
O EROS EM UMA SOCIEDADE CANSADA: UMA BUSCA NARCISISTA PELO OUTRO ATRAVÉS DOS VIDEOGAMES
}

DOI: https://doi.org/10.33871/23580437.2020.7.2.114-129

\author{
José Antônio Loures ${ }^{1}$ \\ Caio Túlio Olímpio Pereira da Costa ${ }^{2}$
}

\begin{abstract}
Resumo: O artigo se propõe a discutir os videogames como meio para o preenchimento de uma lacuna entre as relações humanas. Em uma sociedade cansada, a busca por afeto através do outro como reafirmação das próprias crenças e realidade. Esse quadro, por sua vez, tem sido constantemente reafirmado nos cenários de pandemia da Covid-19. Nesse sentido, os videogames e jogadores estão inseridos em uma hiper-realidade que oferta o webnamoro. Além disso, relacionamos respostas de um questionário realizado com 1121 participantes acerca dos videogames e sexualidade, com o cosplay em um contexto pós-humano. E por fim, uma entrevista com Lola Waifu, uma acompanhante que atende seus clientes de cosplay de personagens de videogames.
\end{abstract}

Palavras-chave: videogames; sexualidade; hiper-realidade; cosplay; pós-humanismo.

\section{THE EROS IN AN EXHAUSTED SOCIETY: THE NARCISSISTIC SEARCH FOR THE OTHER THROUGH VIDEO GAMES}

\begin{abstract}
The article aims at the discussion of video games as a path to fulfillment of gaps between human relations. In an exhausted society, the search for affection through others as a reaffirmation of its own beliefs and reality. This environment, on the other hand, has been constantly reenforced on the context of the pandemic corona virus. Furthermore, video games and its players are embedded in a hyper-reality that offers web dating. Moreover, the authors relate answers of a survey carried out with 1121 participants concerning video games and sexuality, carrying out the spotlight on the cosplay in a post-human context. Additionally, the article contextualizes an interview with Lola Waifu, an adult escort who serves her customers wearing video games characters cosplays.
\end{abstract}

Keywords: Video Games; Sexuality; Hyper-Reality; cosplay; post-humanism.

\footnotetext{
${ }^{1}$ Artista multimídia e Doutor em Artes pela Universidade de Brasília. Mestre em Arte e Cultura Visual pela Universidade Federal de Goiás. Também pesquisa sobre transhumanismo, jogos de tabuleiro, cibercultura e práticas divinatórias. Email: jloures-arte@hotmail.com

${ }^{2}$ Doutorando em Educação Tecnológica pela Universidade Federal de Pernambuco. Mestre em Comunicação pela Universidade Federal de Pernambuco. Membro do Grupo de Pesquisa Mídias Digitais e Mediações Interculturais (CNPq: Edumatec/UFPE).E-mail: caiotuliocosta3@gmail.com.
} 


\title{
EL EROS EN UNA SOCIEDAD AGOTADA: LA BÚSQUEDA NARCISISTA DEL OTRO A TRAVÉS DE LOS VIDEOJUEGOS
}

\begin{abstract}
Resumen: El artículo tiene como objetivo discutir los videojuegos como uma forma de llenar los vacíos entre las relaciones humanas. Em uma sociedade agotada, la búsqueda del afecto a través de los demás como reafirmación de sus propias creencias y realidade. Este entorno, por otro lado, se ha reforzado constantemente em el contexto de la pandemia de coronavirus. Además, los videojuegos y sus jugadores están integrados em uma hiperrealidad que oferece webcitas. Por outra parte, los autores informan de las respuestas de uma encuesta realizada a 1121 participantes sobre los videojuegos y la sexualidade, poniendo el foco em el cosplay em um contexto poshumano. Además, el artículo contextualiza uma entrevista com Lola Waifu, uma escort adulta que atende a sus clientes vistiendo cosplays de personajes de videojuegos.
\end{abstract}

Palabras-clave: videojuegos; sexualidad; hiperrealidad; cosplay; poshumanismo.

\section{Introdução}

Dentre todas as expressões de nossa identidade e cultura digital, os videogames detêm lugar privilegiado nas discussões contemporâneas sobre interação, convergência e diálogos entre o real e virtual. Esse caso é reforçado, por exemplo, quando consideramos a Pesquisa Game Brasil 2020, enquanto censo demográfico e cultural que perfila o jogador brasileiro, e suas revelações de que a maior parte dos jogadores no país é composto por mulheres $(61,9 \%)$ com idade entre 25 e 34 anos $(35,2 \%)$, que se enquadram no perfil de jogadores casuais - jogam até horas por semana em sessões de até três horas de duração. Já entre os homens $(61,3 \%)$ com idade entre 16 e 24 anos $(39,2 \%)$, por outro lado, se consideram em grande maioria jogadores hardcore - perfil de consumidor que se dedica a obter os meios mais caros e evoluídos tecnologicamente para consumir os jogos digitais (SIOUX; BLEND; ESPM, 2020). Nesse contexto, também por suas relevâncias acadêmicas, sociais e mercadológicas, os jogos digitais já estão estabelecidos em nosso cotidiano e cultura pós-moderna. Nessa perspectiva, atualmente, o videogame não oferece apenas entretenimento, mas também uma possibilidade de afeto entre os jogadores.

De acordo com Han (2015), a sociedade atualmente se caracteriza pelo desaparecimento da alteridade e da estranheza. Não entramos mais em contato com aqueles que são diferentes de nós. Em um sistema dominado pelo igual, não faz sentido fortalecer o nosso sistema imunológico (HAN, 2015). Nesse sentido, emerge uma busca identitária através da validação do descobrimento do outro (GIDDENS, 1992). Assim somos sucessíveis a cada vez mais confirmações de nossas crenças, e menos encontros e ameaças com o diferente e ao diálogo.

As formas como nos relacionamos com o outro está em constante mudança. O amor como conhecemos está desaparecendo devido a multiplicidade e liberdade de opções, além de um sistema opressor de desempenho (HAN, 2017). Nesse contexto, se oferecem novas maneiras de se encontrar afeto, e algumas delas envolvem diretamente os videogames. Contudo, em tempos de pandemia essa realidade ainda se alastra a partir a partir de mudanças significativas diárias no curso da normalidade. Percebemos fenômenos sociais migratórios que acabam por culminar em reuniões de trabalho por meio do Skype, dos aniversários pelo Zoom, pelos canais de comunicação home office pelo Google Meet, dentre diversos outros. Essa integração real-virtual causada pela pandemia da Covid-19 
ressignifica, impreterivelmente, os modos de nos relacionarmos e interagirmos com tudo à nossa volta. As tendências afetivas nesse contexto são potencialmente mudadas pelas tecnologias da contemporaneidade de forma incisiva (PUAR, 2017). Os algoritmos, em suas respectivas plataformas, são responsáveis por viabilizar e mediar fenômenos sociais em tempos de pandemia, $o$ que acaba por abrir possibilidades, inclusive, para uma distinta forma de envolvimento entre usuários, indivíduos e suas ambiências digitais, conforme atestam Van Djick, Poell e Waal (2018). Entre tal recorte e contextualização, portanto, nos atentaremos aos relacionamentos pós-modernos e suas reverberações no cotidiano regular dos jogadores.

O eros agora está presente em uma hiper-realidade cada vez mais cotidiana e com uma crescente tendência de busca por afeto com os games como estopim. Um sistema que oferece ao jogador e interator (MURRAY, 2003) a possibilidade de alugar uma namorada(o) para se jogar uma partida de League of Legends (2009) e uma acompanhante para realizar fetiches por um determinado personagem de videogame.

\section{Os afetos perante a tela escura}

Há uma geração com novas maneiras de se demonstrar afeto e a sua própria sexualidade, que cresceu e foi alimentada por termos como "webnamoro". Essas relações têm como característica uma procura mútua por um igual através da internet, sob um estreitamento de laços separado por telas e interfaces computacionais/tecnológicas. Contudo, por muitas vezes, o webnamoro é visto como uma piada nascida nas redes sociais, e existe até mesmo uma página no Facebook dedicada a divulgar prints de webrelacionamentos. Também podemos nos deparar, em simples buscas sobre o termo em interfaces de buscas online, com manuais que ensinam como se iniciar na prática, inclusive com instruções passo a passo (fig. 1):
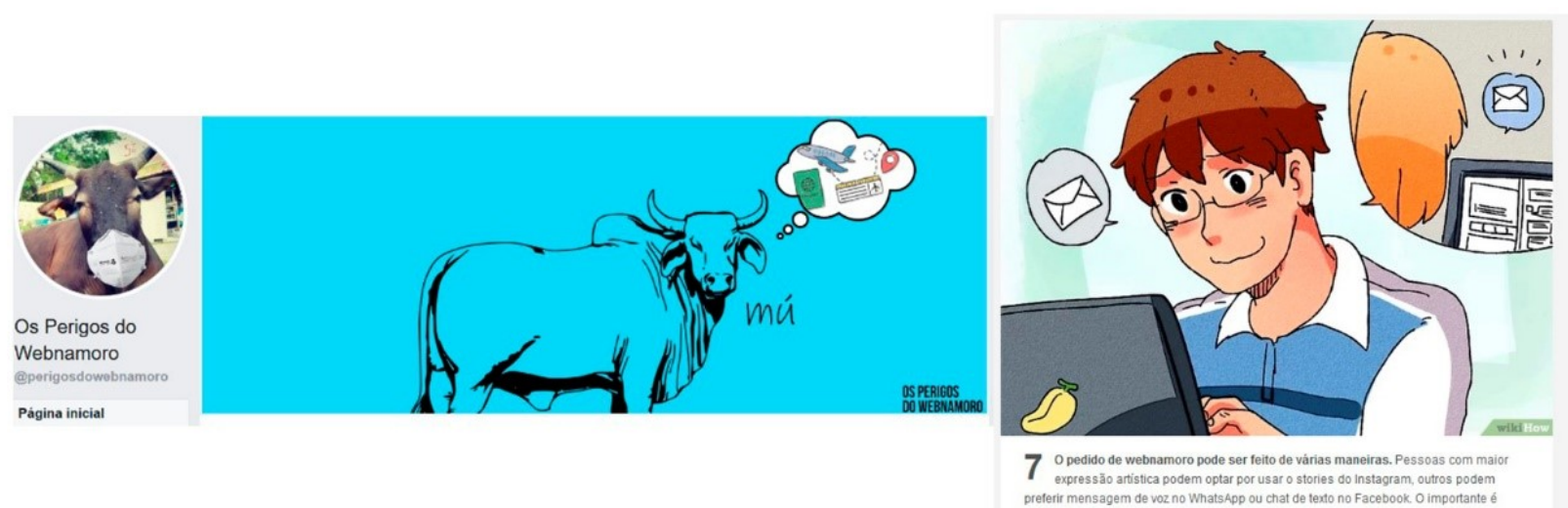

Figura 1 - Página "Os Perigos do Webnamoro". Fonte:

https://www.facebook.com/perigosdowebnamoro/. Guia de como Webnamorar. Fonte: https://pt.wikihow.com/Webnamorar.

Esteticamente, a prática é relacionada aos jogos online e também ao consumo da cultura japonesa como os animes e games. Logo, o capitalismo se apropriou do "webnamoro" criando um sistema de oferta e procura. Encontramos páginas na internet com anúncios de pessoas se alugando para ocupar o papel de webnamorada(o) por um determinado período. O serviço oferece: conversar, jogos online, assistir animes e filmes, e também a opção de enviar fotos/vídeos sensuais (fig. 2): 


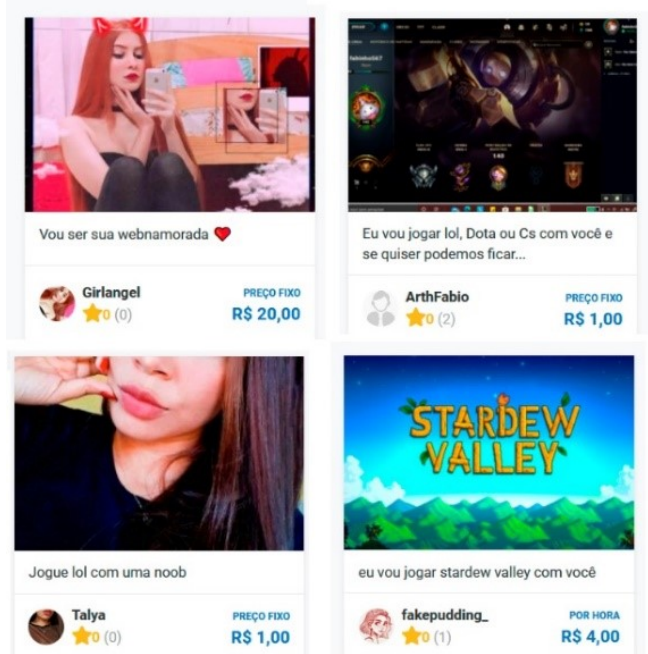

Figura 2 - Serviços de webnamoro. Fonte: https://gamlng.com.br.

A hiper-realidade surge quando uma simulação se desprende do seu referencial e ganha autonomia para existir (BAUDRILLARD, 1991). Nessa instância, vem à tona uma percepção de que a tecnologia, quando inserida de forma ubíqua no contexto social do indivíduo, acaba por colocá-lo em uma posição de fascínio e risco, evidenciando, portanto, uma questão de ordem filosófica que exige postura crítica em seu trato contemporâneo (JOBIM E SOUZA; GAMBA JR., 2002). Nesse o contexto, o ficcional se torna mais que real. Assim, no webnamoro se perde o referencial, e resta apenas a construção de uma persona nas redes sociais e demais páginas de encontros. Uma busca por afeto numa sociedade cada vez mais distante do toque, ainda mais no atual momento de isolamento social devido a pandemia da Covid-19. Os ambientes digitais ganham mais importância do que a realidade carnal. Nesse sentido, as redes sociais são usadas para elevar a autoestima através de uma procura por afeto:

O sujeito de desempenho está livre da instância externa de domínio que o obriga a trabalhar ou que poderia explorá-lo. É senhor e soberano de si mesmo. Assim, não está submisso a ninguém ou está submisso apenas a si mesmo. É nisso que ele se distingue do sujeito de obediência. A queda da instância dominadora não leva à liberdade (HAN, 2015, p. 16).

A necessidade de mostrar o seu desempenho perante a internet e aos amigos residentes nas redes sociais. Uma incessante exploração de si para se sentir acolhido na busca por um companheiro, e em determinados casos um companheiro alugado. Podemos atribuir essa tendência contemporânea, primordialmente, por uma espécie de plataformização da vida, que em outras circunstâncias e perspectivas poderiam ser concebidas como uma herança digital da sociedade do espetáculo. Percebemos que a hiper-realidade, potencializada por essa plataformização, é responsável por interferir diretamente nas tendências afetivas e afetações dos corpos. Nesse contexto se mudam as práticas, a economia de atenção, os modos de se relacionar e produzir subjetividades (PUAR, 2017). O importante é como somos vistos no ambiente digital, e não os bastidores e nem os caminhos trilhados para se adquirir esse objetivo. Não importa se a namorada é contratada por uma semana, mas sim o impacto causado nas redes sociais durante esse período. Pois se paga para receber atenção e afeto:

Hoje, o amor se positiva em sexualidade, a qual está também submissa à ditadura do desempenho. Sexo é desempenho. Sexyness é capital que precisa ser multiplicado. O corpo, com seu valor expositivo equipara-se a uma mercadoria. O outro é sexualizado como objeto de excitação. Não se pode amar o outro, a quem se privou de sua alteridade; só se poderá consumi-lo. Nesse sentido, enquanto for fragmentada 
num objeto parcial sexual, não será ainda uma pessoa. Não existe personalidade sexual (HAN, 2017, p. 14).

O outro se torna apenas um objeto escravo do consumo, e com isso a morte da alteridade. Nesse momento a projeção e aquele que projeta são transformados em mercadoria e colocados de joelhos perante ao sistema capitalista. Existe a projeção dos desejos e fetiches com o objetivo de uma satisfação narcisista. O capitalismo

vai eliminando por toda parte a alteridade a fim de submeter tudo ao consumo. Além do mais, o eros é uma relação assimétrica com o outro. Assim, ele interrompe a relação de troca. Sobre a alteridade não é possível estabelecer um registro de controladoria. Ele não entra no balanço dos débitos e créditos (HAN, 2017, p. 17).

Para Han (2017) o eros é uma relação assimétrica, nesse sentido, o capitalismo é uma relação simétrica por nos subjugar a condição de consumidor e mercadoria. Através da alteridade não controlamos o outro, então a possibilidade de pagar para receber afeto, carinho e sexo se mostra um caminho eficaz. A necessidade de reafirmar os nossos desejos e crenças através de um serviço, e assim realizar tudo aquilo que é colocado a margem da sociedade.

\section{O cosplay pós-humano}

O cosplay é a união entre o vestir e interpretar um algum personagem (NUNES, 2013). Há uma comunidade de cosplayers dedicada a criação de roupas, acessórios, maquiagem e outros aspectos responsáveis por trazer um personagem para a nossa realidade. A criação de um mundo imaginário caracterizado pela diversão e liberdade (MARTINS, 2015). Em um determinado tempo e espaço, não existe alguém interpretando um personagem, mas somente o personagem em um cenário de hiperrealidade. O sentir, nesse contexto, é uma das qualidades mais ressignificadas em tempos pósmodernos. É a partir de uma emoção ou uma sensação que o indivíduo é levado a se mover. A indignação leva à luta, o amar leva ao compartir afeto e assim por diante.

E é através dessa dinâmica que às vezes conseguimos dar vazão a determinados sentimentos e vontades. Vivendo o avatar ou o personagem para simular a comunhão entre o que é possível no momento e o que realmente se quer fazer. A tentativa de satisfazer certos desejos através do imaginário construído naquela situação de hiper-realidade. Contudo, os cosplayers interpretam personagens que por muitas vezes estão além das nossas capacidades biológicas.

Entre 24 de março e 18 de agosto de 2018 empregamos um questionário online com 1121 participantes sobre sexualidade e videogames ${ }^{3}$, fruto da tese de doutoramento "Homo sex ludens: a sexualidade nos videogames" pelo Programa de Pós-graduação em Artes Visuais - UnB (LOURES, 2020). O questionário foi dividido em três seções: A primeira sobre informações acerca da idade, gênero, orientação sexual, residência, religião, estilo de jogos digitais preferidos e profissão dos participantes; A segunda acerca sobre as experiências dos participantes com jogos com cenas sexuais, e em quais jogos e séries tiveram os primeiros contatos; E a terceira parte focada no desejo sexual, masturbação, pornografia e fetiche por personagens de videogames e cosplayers. É importante dizer que apenas a primeira etapa exigia resposta, e todas as demais poderiam ser evitadas caso o participante desejasse não responder. Esse questionário foi divulgado em grupos em redes sociais (Facebook e WhatsApp) dedicados a pesquisa acadêmica, Universidade Federal de Goiás e Universidade de Brasília, jogos de videogames e animações/mangás japoneses. O objetivo desse questionário era compreender quais eram as percepções e relações dos participantes sobre a presença

\footnotetext{
$3 \mathrm{O}$ formulário aplicado via questionário do Google pode ser acessado em: $<$ https://docs.google.com/forms/d/1IuTwHQQ3ohwVVnZViBPyNaSI0ZS5oSNedl2wFyAB6hA/closedform>.
} 
de cenas sexuais nos jogos digitais e também os diversos graus de envolvimento afetivo e sexual com personagens de videogames. Após isso foi realizada uma análise e mineração de dados para conhecer o perfil dos participantes e obter informações relevantes sobre o tema.

Assim foi revelado que 19\% apresenta o desejo de ter relações sexuais com um cosplay, o gênero de quem já fez sexo com cosplay, e a faixa etária daqueles que ainda não realizaram essa fantasia (fig. 3):

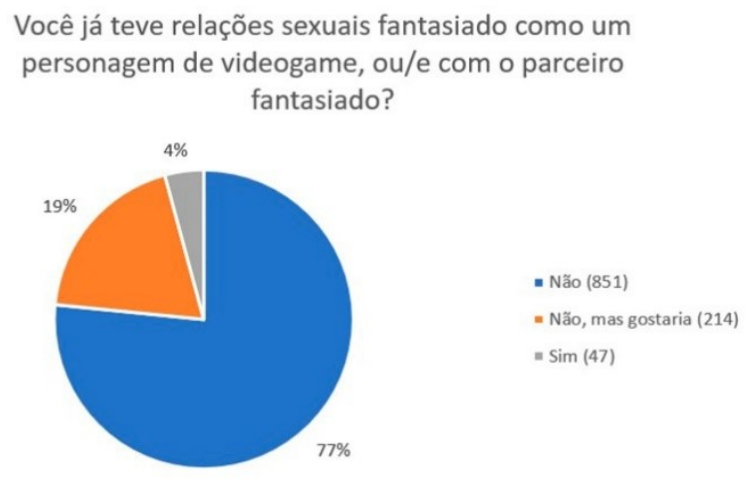

Gênero de quem já fex sexo de cosplayer e/ou com um cosplayer
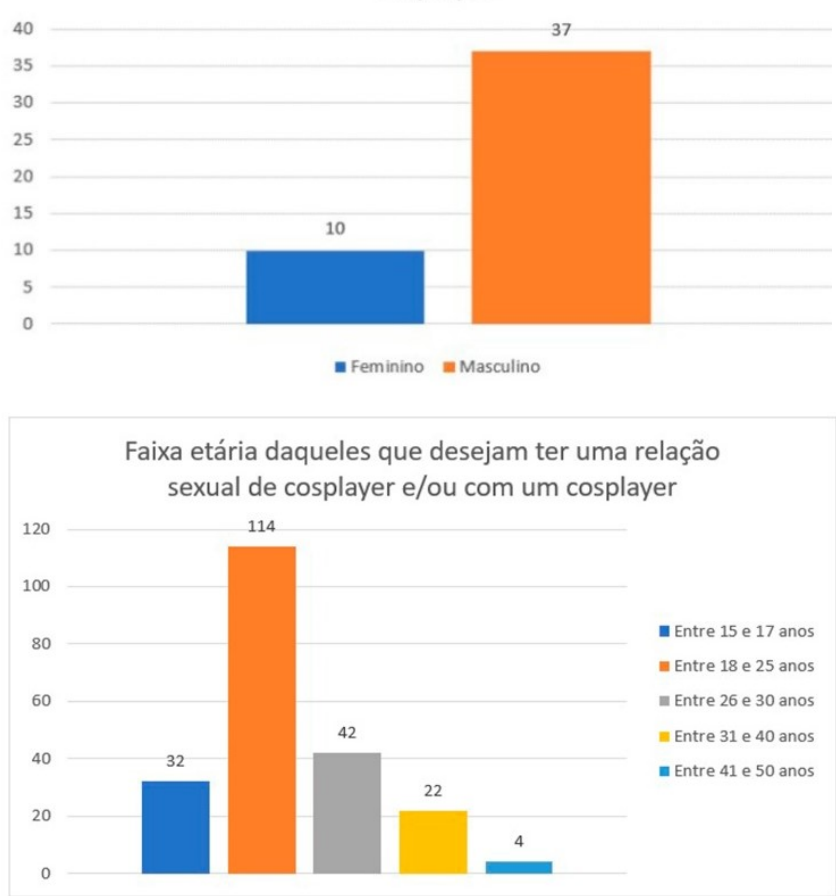

Figura 3 - Resultado parcial do questionário aplicado a partir de Homo sex ludens (LOURES, 2020). Fantasias sexuais com cosplay de personagens de videogame / Gênero de quem já fez sexo de cosplay ou com cosplay e faixa etária daqueles que desejam, mas ainda não tiveram relações sexuais com um cosplay.

De acordo com a pesquisa, quando relacionamos sexualidade e o cosplay de videogames encontramos majoritariamente o seguinte perfil de jogador: homem entre 18 e 25 anos. Nesse contexto, os jovens concentram o maior interesse sobre o assunto, e ainda podemos relacionar a prática como uma possível objetificação da mulher. O sexismo transcende o digital, contudo, os games privilegiam esse tipo de comportamento (FORTIM; PIRRO, 2019). E isso se aplica aos universos gerados em volta dos videogames, como o cosplay. Assim como em todos os lugares, mídias e em instituições de poder 
(SHAW, 2014). A relação entre o imaginário e a experiência de habitar esses universos, mesmo que momentaneamente, tende a gerar uma fruição a partir da interatividade que age como disparador cognitivo de sensibilidades e sensações, e até mesmo emoções, que podem revelar uma mínima parcela de efeitos e práticas que constituem um oceano de possibilidades que podemos imergir. Um mergulho em águas primorosamente simuladas.

Para Giddens (1992, p. 42): “O corpo tem sido sempre adornado, acarinhado e, às vezes, na busca de ideias mais elevados, mutilado e debilitado". Nesse sentido, o homem sempre buscou alterar o próprio corpo, contudo, atualmente existe uma busca irreal que vai além de padrões de beleza, pois há uma necessidade por corpos que não são humanos em sua essência. Talvez por isso o desejo sexual por personagens de videogames tenha buscado uma corporalidade para habitar. Assim surge um termo

popular na atualidade entre filósofos, cientistas sociais e artistas é o "pós-humano", neologismo que tem como um dos seus significados possíveis mais difundidos a expansão e diluição do corpo e consciência humana através do acoplamento crescente com as novas tecnologias: robótica, telemática, nanoengenharia, biogenética (FRANCO, 2010, p. 100-101).

O pós-humano é utilizado para abordar as possibilidades decorrente de uma nova corporalidade na contemporaneidade. A corporalidade humana é resultado de viver conversações em diversos modos (MATURANA, 2001). Estamos vivenciando um momento singular, onde a digital toca e pode ser tocado pelo material, a transição dos pixels para a carne. O artista e pesquisador Roy Ascott (2003) nomeia esse encontro de realidade mista. O cruzamento de arte, ciência e tecnologia, em um contexto onde o mundo virtual é sintetizado no mundo real. $\mathrm{O}$ autor aposta no surgimento de uma tecnologia que propicie uma integração quase perfeita entre o mundo real e virtual. É possível que os videogames sejam essa tecnologia, e também o caminho para tornar a realidade mista acessível.

Nesse contexto, os personagens de videogames e animes não seguem os mesmos padrões de um corpo humano, pois existe uma intencionalidade artística de criar algo ficcional com os corpos dos personagens. A sexualidade em uma era pós-humana apresenta um corpo desassociado dos órgãos e dos prazeres, assim restando apenas cicatrizes vazias sem referências e limites (BAUDRILLARD, 1992).

Por exemplo, as personagens femininas dos jogos de luta são construídas para atender a demanda por um desejo de jogadores cisgênero de videogames. O desenvolvimento dos aspectos visuais e dos golpes aplicados em cena são pautados para provocar o jogador homem e heterossexual. Assim existe um mercado oficial por roupas (skins) que deixem as personagens com mais partes do corpo a mostra e um visual mais atraente, e também por meio de um mercado não oficial com o consumo de modificações sexuais via financiamento coletivo (LOURES, 2017).

De acordo com Baudrillard (1992) o desejo sexual sempre foi mediado por aparatos técnicos em um processo mecânico relacionado com a fantasia, mas com uma manipulação mediada por gadgets. As personagens femininas em jogos de luta realizam esse desejo através de um corpo sem culpa, sem órgãos, esse construído para o prazer dos jogadores através da destruição de seus corpos digitais. Uma necessidade por moldar e construir um corpo feminino assim como adolescentes conseguiram em Uma mulher Nota 1000 (1985). 


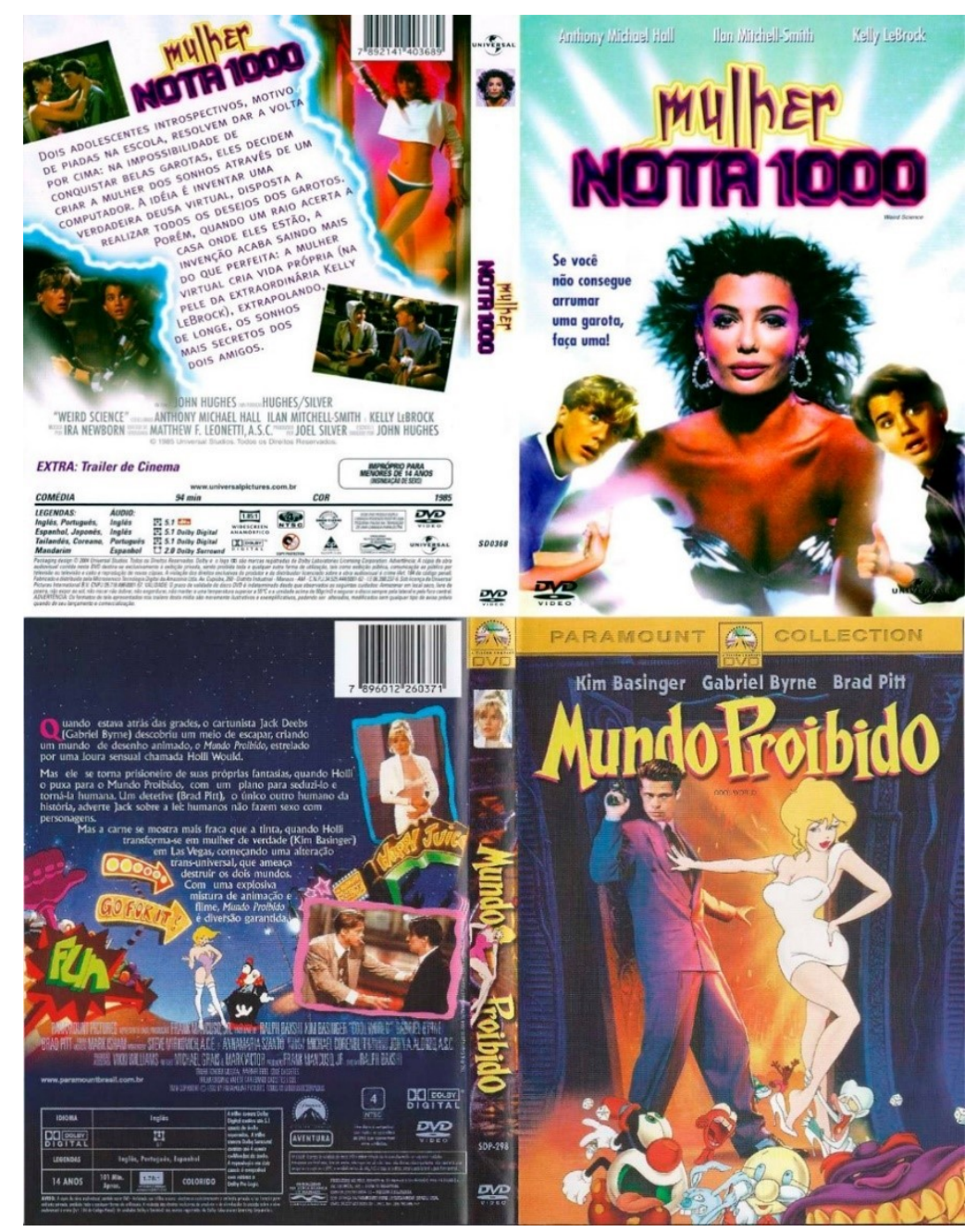

Figura 4 - Capa do DVD do filme "Mulher nota 1000” e "Mundo Proibido”. Fonte: Mercado Livre.

Já em Mundo Proibido (1992) há tensão sexual entre o protagonista interpretado por Brad Pitt e Holli Would, uma sinuosa personagem de desenho animado é um dos pontos centrais na trama (fig. 4). Nesse sentido, também existe o desejo por possuir as personagens em seu estado bidimensional desde comissões e modificações sexuais para games (Fig. 5):

Você se sente atraído sexualmente por personagens de videogame?
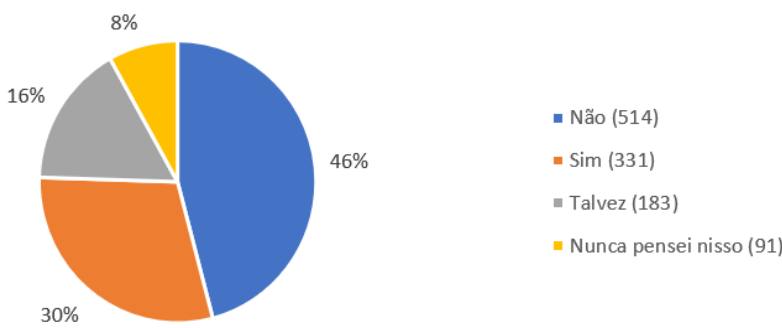

Figura 5 - Atração sexual dos participantes por personagens de videogame.

Para Mark Dery (2000):

Apesar de tudo, a especulação corrente em relação à sexualidade pós-humana está limitada pelo facto inescapável que é conduzida do ponto de observação privilegiado 
dos seres humanos, para quem a própria noção de sexualidade é definida em termos de corpo e de humanidade (DERY, 2000, p. 251).

Tanto a representação corpórea dos personagens de videogames (cosplayers) quanto a representação bidimensional (personagens de games) são usadas como espelho para servir um desejo masculino e narcisista (DERY, 2000). Em ambos os casos, uma representação feminina dos desejos masculinos em um grau que nenhuma fêmea humana poderá ocupar (BURNS, 2014). Seres que se encontram um terreno híbrido entre a falsificação da vida (MATURANA, 2001) e a hiper-realidade (BAUDRILLARD, 1991) na construção de uma realidade mista (ASCOTT, 2003). Nesse contexto, os videogames são uma possibilidade para novas interações e interpretações sobre a função do corpo humano, em um ambiente asséptico propicio para a discussões acerca da noção de sexualidade, corpo e humanidade. Nesse campo entrelaçado a experiência humana de habitar elementos do videogame é capaz de intensificar transformações do real, "muito embora essa relação deva comportar, para ser completa, uma corporização externa estimuladora do organismo" (BURNS, 2014, online).

Percebam que os filmes citados acima apresentam uma perspectiva masculina e fetichista do corpo da mulher. Então realizei uma entrevista para trazer uma outra perspectiva além daquela encontrada através do consumidor-rei - jogadores conservadores, cisgênero de alto poder aquisitivo que impõem como deve ser uma experiência ao se jogar um videogame (LOURES, 2017). Mas que também corrobora com a ideia de que o cosplay é um dos caminhos para a inserção da sexualidade nos videogames em nosso cotidiano.

\section{Entrevista com Lola Waifu}

Lola Waifu é uma modelo e acompanhante que atende em São Paulo, com o diferencial de focar no público nerd e também por atender de cosplay. Em junho de 2020 entramos em contato com Lola via redes sociais, e foi realizada uma entrevista sobre sua profissão e como os videogames interferem em seu trabalho e com a relação com seus clientes.

Lola possui uma página oficial onde estão informações, valores, serviços, fotos e contatos. Então a primeira pergunta foi: - Na sua página oficial é evidente o seu interesse pelo universo geek e nerd. Até que ponto seu interesse por esses temas te incentivou em seu trabalho?

Eu não acho que o universo geek e cultura pop e tudo mais tenha influenciado no meu trabalho, e na minha ideia de trabalhar com isso. Eu acho que provavelmente a única influência que teve foi a questão que se você está mais na internet se está em contato com coisas novas e diferentes, você tem uma mente aberta. Então chegou um dia em que me questionei "por que não? Não é mesmo", e foi isso. Não acho que tenha tido a ver diretamente com o mundo nerd (LOLA WAIFU, 2020, online).

Apesar de Lola afirmar que o universo nerd, incluindo os videogames não tenham incentivado o seu trabalho, em sua página encontramos uma tabela de habilidades semelhante à aquelas que encontramos em jogos de RPG - Role Playing Game ou jogo de interpretação de papéis, ou seja, existe uma apropriação da linguagem dos games na divulgação de sua profissão (fig. 6): 


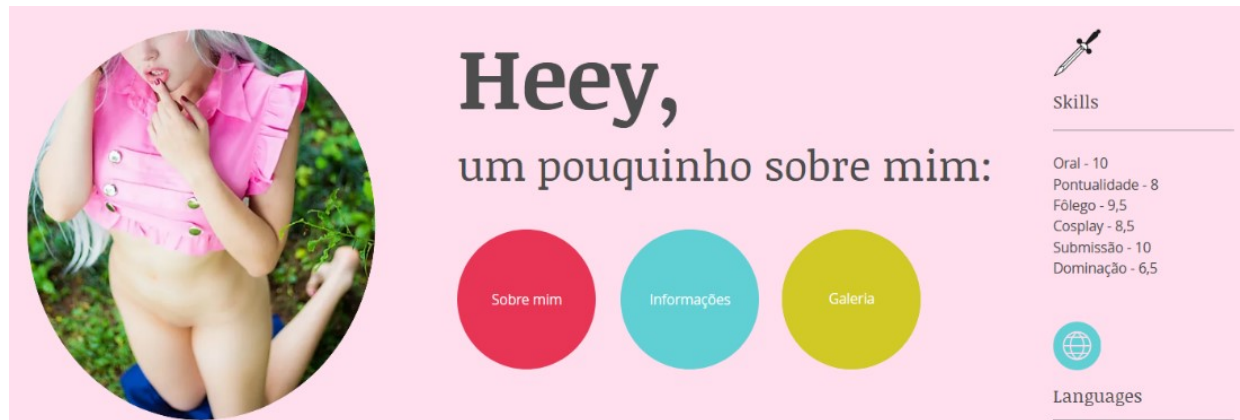

Figura 6 - Página oficial de Lola Waifu. Fonte: https://lolawaifu.wixsite.com/lolawaifu.

A segunda pergunta: - A partir de qual momento você enxergou o trabalho sexual com o cosplay como uma oportunidade de ganhar dinheiro. Existe muita procura?

Tem bastante procura sim, e faço os meus cosplays com bastante trabalho e esmero. Mas muitas vezes a pessoa nem está tão preocupada com os detalhes e tudo mais. Muita gente que faz atendimento com cosplay realmente nem tira o cosplay durante o atendimento e muitas vezes não quer nem o sexo e sim ter um tipo de relação, algum tipo de coisa. Então é realmente pelo cosplay, eu passo a maior parte do tempo vestida. E quando veio isso deve ser porque acho bonito, eu como mulher bi sempre achei muito bonito o cosplay. Sempre gostei muito da ideia, acho que todo mundo que joga sempre teve um crush em anime, em jogo. E daí veio a ideia, porque eu gostava também, então imaginei que teria mais gente que curtisse (LOLA WAIFU, 2020, online).

Lola tem 21 anos de idade, e pertence a uma geração que cresceu com inovações tecnológicas já consolidadas e massificadas através da acessibilidade proporcionada pela internet. As respostas do questionário revelaram uma atração sexual entre os jogadores e os personagens de videogames, e Lola também corrobora isso ou dizer que "todo mundo que joga sempre teve um crush em anime, em jogo". Crush, nesse sentido, representa a palavra originada na língua inglesa que significa "colisão" ou "queda", mas que ganhou significado de uma paixão e interesse por alguém. Geralmente esse sentimento não é revelado, sendo mantido em segredo, algo que reverbera do platônico. Esses personagens são transformados em objetos para os consumidores de pornografia. Existe uma potência exacerbada na pornografia, que resulta em uma total sexualização da realidade, ou seja, a erotização de toda a percepção que um sujeito tem do mundo a sua volta (BURNS, 2014). É interessante perceber em sua resposta que existem clientes que não buscam apenas sexo, e sim afeto, ou seja, a necessidade de se conectar com outro ser humano, nem que seja através da prestação de um serviço.

Lola também diz que existem outras acompanhantes que são cosplayers ou seja, existe todo um de mercado já estabelecido, mesmo que não seja tão comentado e divulgado. A partir disso, a terceira pergunta foi: - Você oferece seus serviços também de cosplay, com ou sem interpretação. Pode exemplificar as diferenças entre ambos?

A diferença é que sem interpretação sou eu, Lola, vestida de cosplay encontrando você, seja quem você for. Com interpretação é importante eu conhecer todos os personagens que eu faça cosplay, são todas personagens que eu gosto ou então que já gostei. Enfim, eu tento dar uma olhada na história da personagem, dou uma revisadinha, e converso com a pessoa como se eu fosse essa personagem, ela me trata por esse nome e é assim. É uma coisa muito bem conversada porque algumas delas (personagens) não consigo imaginar como ela se comportaria em uma situação sexual. Por exemplo a 2B (Nier: Automata) ela é um androide, então eu falo "talvez não seja uma coisa tão quente, assim cheia de reações". Eu imagino como essa 
personagem agiria numa situação assim. Então essa é a interpretação (LOLA WAIFU, 2020, online).

De acordo com Lola existe toda uma preocupação com o processo de construção do cosplay até chegar o momento do atendimento. Essa ação flerta com os jogos de interpretação de papéis, devido a necessidade de compreender a personagem escolhida em situações inéditas em uma narrativa sexual através da mediação do mestre (cliente). Podemos relacionar essa ação com as práticas encontradas no BDSM (Bondage, Disciplina, Dominação, Submissão, Sadismo e Masoquismo), e também nas informações encontradas na tabela de habilidades de Lola: submissão 10, e dominação 6,5.

Nier: Automata foi lançado em 2017, e apesar de ser um jogo recente a protagonista 2B apareceu na décima posição em meu questionário, próxima a personagens com décadas de existência.

Ainda sobre os pedidos dos clientes, a quarta pergunta foi: - Quais os cosplays mais pedidos? Seus parceiros(as) também usam cosplays durante os encontros? E durante o ato eles solicitam gestos relacionados às personagens?

Os cosplay mais pedidos dependem muito de tempo. Eu fui fazer um intercâmbio na Alemanha, e estou fora do Brasil faz 1 ano, então eu não sei exatamente por agora por causa da quarentena, não voltei a trabalhar direito também ainda. Mas eu lembro que antes pediam muito colegial, que nem é um cosplay, ou então a 2B do Nier: Automata é muito pedida. A Ravena (Teen Titans) é muito pedida também e tinha a Rem de Re:Zero, é eu acho que eram essas. Se tem algum gesto referente a personagem, depende. Na maioria das vezes na verdade, não, e se tiver é algo que eu converso com a pessoa antes. Tem gente que gosta daquele eu não sei como se falar, ahegao, a carinha. É o que mais pedem, mas não é relacionado a nenhum personagem é um carinha de hentai (LOLA WAIFU, 2020, online).

É comum encontrar desenhos, animações e produções pornográficas envolvendo a personagem 2B (fig. 7):

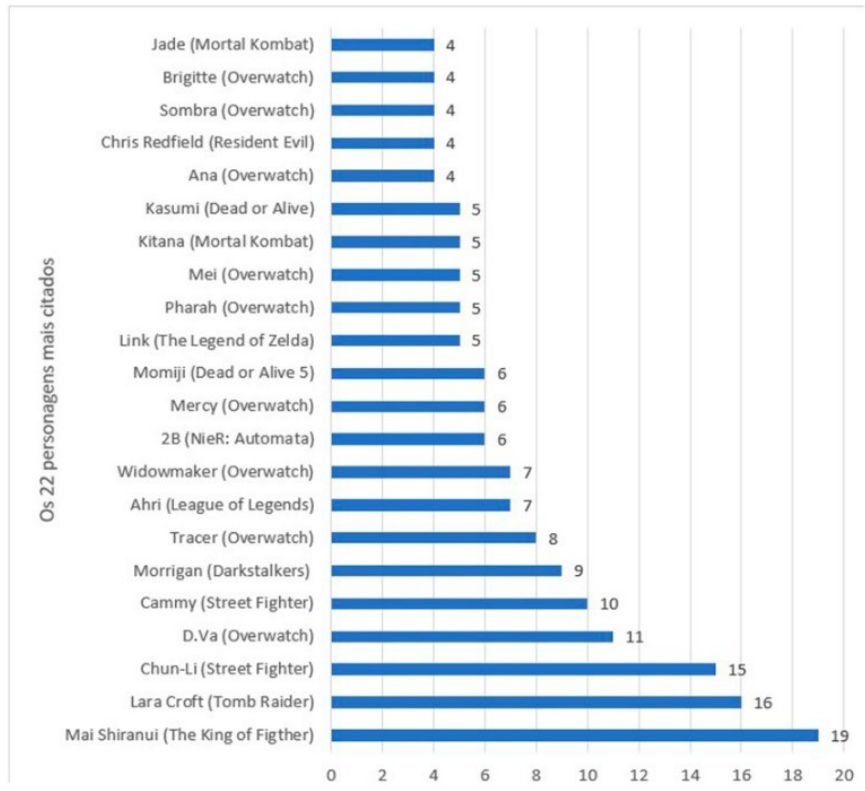

Figura 7 - Excitação por personagens de videogames (LOURES, 2020)

Assim como imagens de Lola de cosplay da personagem (fig. 8): 


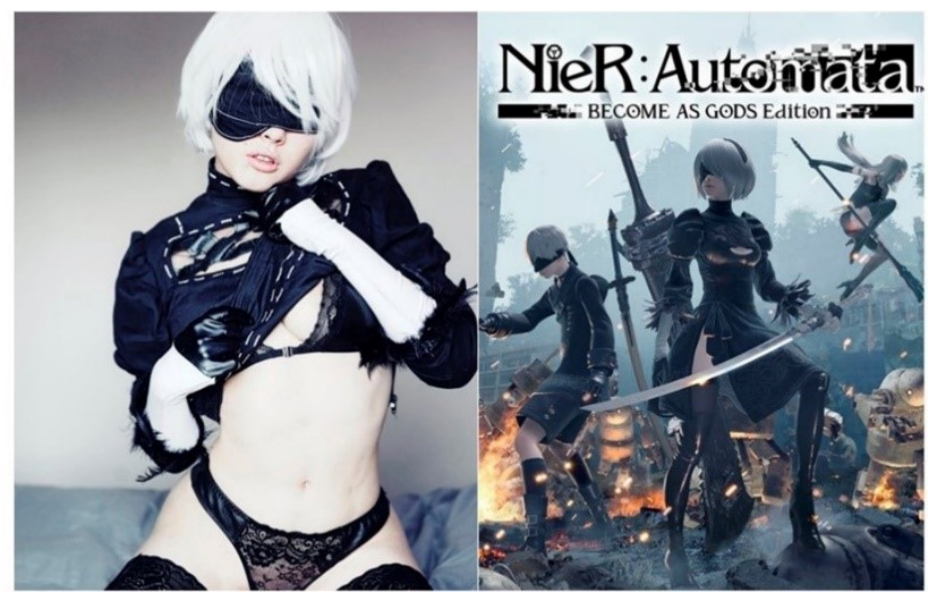

Figura 8 - Lola Waifu de 2B de Nier: Automata. Fonte: https://twitter.com/Lola_Waifu

Mais um exemplo da transição de um personagem bidimensional para um cenário sexual em nosso cotidiano. Além disso, Lola cita o ahegao - representação gráfica e exagerada do prazer feminino encontrado em histórias em quadrinhos pornográficas japonesas (MORAES; LAPEIZ, 1985) Essa "carinha" apresenta características pós-humanas em um contexto de hiper-realidade (fig. 9).
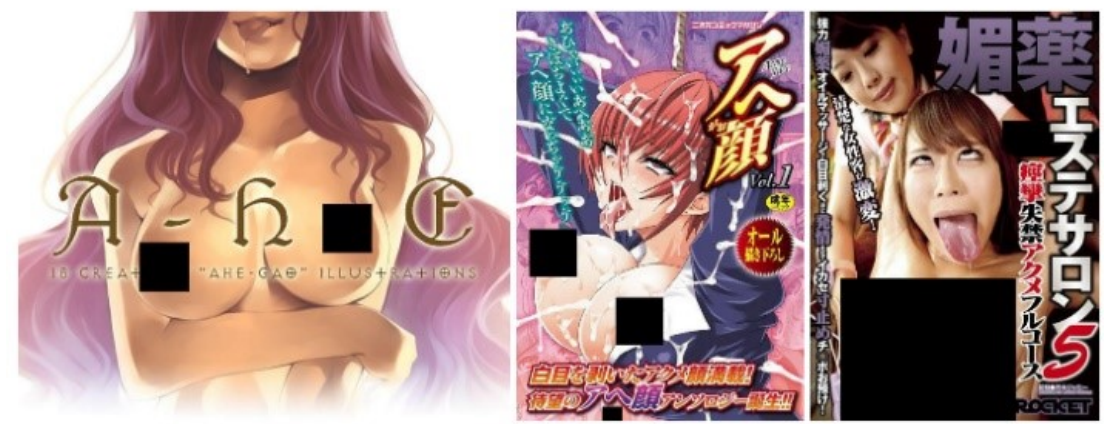

Figura 9 - Exemplos de ahegao em mangá e em filmes pornográficos. Fonte: knowyourmeme.com.

É no mundo da imaginação que o exagero é permitido, e se torna impossível diferenciar o que é fícção e o que é realidade (DUARTE, 2017). Assim, a quinta pergunta - Já atendeu algum cliente de cosplay de personagem de videogames? Como foi o contato do cliente sobre o pedido dessa fantasia?

Já, e eu não entendi. A pessoa me perguntou sobre os cosplay, eu falei quais eu tinha e ela escolheu o que era de videogame. Acho que é a D.Va (Overwatch), e a 2B (Nier: Automata) que eu tenho de videogame. Acho que tenho outros, eu renovei o meu acervo, eu pedi bastante coisa, mas ainda falta chegar muitas partes da China. E um adendo, meus parceiros não costumam utilizar cosplay, teve apenas uma vez que eu atendi alguém de Stormtrooper (Star Wars) e eu particularmente achei muito legal (LOLA WAIFU, 2020, online).

Desde o trailer de anúncio de Overwatch (2015) o jogo é destaque em páginas pornográficas, e em meu questionário foi o jogo com mais personagens mencionadas para a masturbação, além da personagem D.Va ter ficado na quarta posição entre as mais citadas (fig. 10). 
Séries com personagens mais usados para masturbação

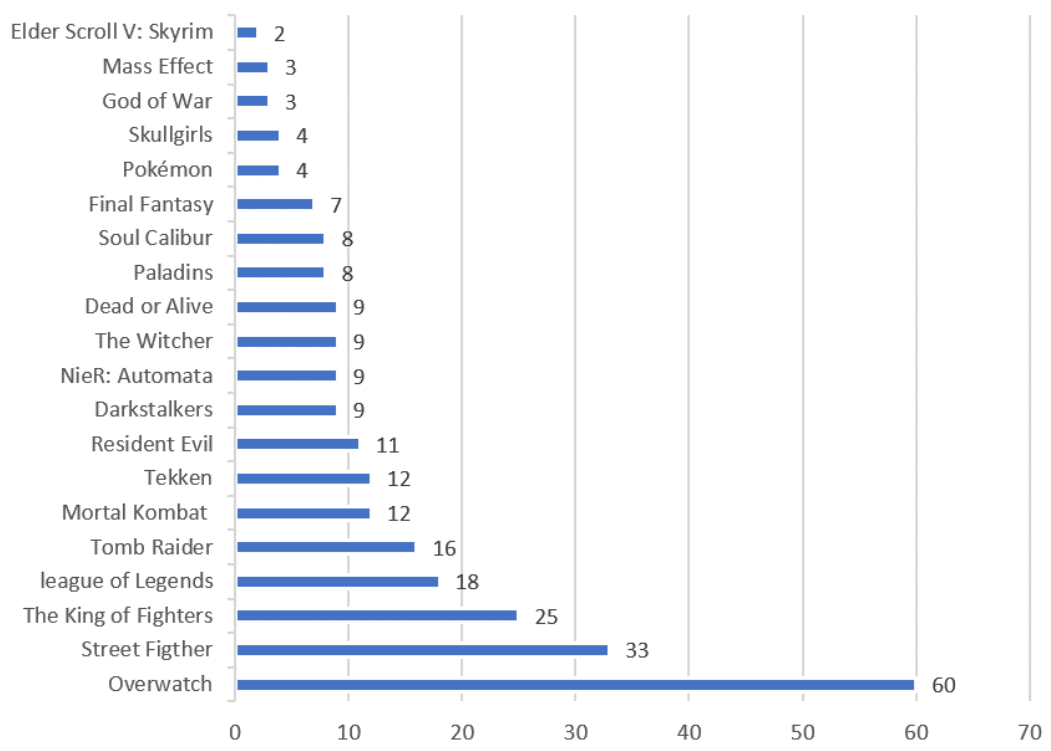

Figura 10 - Séries com personagens mais citadas (LOURES, 2020).

Assim a sexta pergunta teve como objetivo compreender um pouco mais sobre os clientes de Lola: Qual a diferença de perfil (social, gênero e orientação sexual) entre um cliente que pede um encontro com cosplay e os demais clientes?

Um cliente que pede um encontro com cosplay e um que pede sem cosplay na verdade tem o mesmo perfil, porque é o mesmo perfil que gosta de mim. São meninos, homens da idade de 20 até 45 anos, na maioria das vezes muito educados. O público nerd é um público mais tímido, são muitas vezes pessoas introvertidas, e com senso de humor. Acho que o típico nerd (LOLA WAIFU, 2020, online).

É provável que os clientes projetem em Lola os desejos de aceitação que se originaram em contatos com personagens de videogames/animes.

Assim, para encerrar a entrevista a sétima e última pergunta: - qual o personagem de videogames que você deseja, mas ainda não realizou um cosplay? E qual poderia ser a origem dessa atração sexual entre seres humanos e personagens de videogames/animes?

A personagem que queriam muito um cosplay, sempre quis, cheguei a comprar, mas veio quebrado. Tem muito disso também, é por isso que eu cobro a mais pelo atendimento com cosplay. Tem muitas coisinhas para arrumar, muitos detalhes, e que seria a Morrigan do Darkstalkers. Ela não tem muita profundidade que eu saiba, só conheci pelo fliperama e quando você está tentando aprender a desenhar mangá ela sempre aparece em todos os livros como modelo porque é muito bonita, e eu sempre a achei muito bonita. Eu tinha várias páginas, várias coisas dela quando eu era mais nova, desse tipo de revista de desenho até descobrir que era uma personagem. Enfim, eu tenho esse amor platônico pela Morrigan e ainda não consegui fazer cosplay e é um sonho (LOLA WAIFU, 2020, online).

As interfaces por onde o cosplay se reverbera, por sua vez, compõem uma semiosfera, onde os meios de transmissão para a construção de novas (hiper) realidades resultam em novas corporalidades onde é possível vivenciar novos afetos, desejos e consumos (NUNES, 2015). Para Maturana (2001), dialogando com os propostos de Nunes (2015), a realidade é uma noção criada para explicar as nossas experiências. E a usamos de diferentes modos para relatar as nossas vivências. Para o autor, isso justificaria as noções diferentes de realidade em diversas em culturas e em variados momentos. Nesse 
contexto, Lola vive em uma realidade completamente diferente do outro. $\mathrm{Na}$ realidade da acompanhante a participação de uma personagem de videogame impactou a sua noção de belo, ao ponto da cosplayer desejar ser a Morrigan.

Sobre a origem da atração eu acho que para as pessoas por muito tempo é o mais próximo que muita gente tem de ter contato com essas mulheres super bonitas de anime, irreais, que você acha que nunca vai encontrar na vida. São desenhos, 2D, hoje em dia está muito mais real os gráficos de videogames e tudo mais. Eles são semelhantes, são desenhos de forma humana e muita gente que jogou isso não é uma coisa dedicada só ao público adolescente e tudo mais. Mas muita gente cresceu jogando esses videogames, então a gente passou a puberdade olhando para esses personagens bonitos na nossa TV, vendo-os 4 a mais horas por dia, a gente conhece a história deles, a gente vai criando uma admiração e opiniões sobre. Então, acho que é uma questão disso. Tem a ver com essa fase de desenvolvimento que a gente conhece os personagens com essa falsa proximidade que a gente cria com esses seres 2D (LOLA WAIFU, 2020, online).

Existe um fascínio que a cosplayer define como "amor platônico" ao falar sobre a personagem Morrigan. Na entrevista Lola se mostrou pertencente em várias fases dessa corporalidade de personagens de videogame: durante a infância com o seu amor por Morrigan; durante a adolescência em interpretar os personagens; e finalmente na vida adulta realizando os fetiches sexuais que outros tem com a personagens de videogames e com si própria.

\section{Considerações finais}

Temos o webnamoro como uma reverberação dos novos meios de relacionamento da pósmodernidade. Contudo, dificilmente encontramos conteúdo acerca desse assunto, o que resulta em discussões superficiais e por muitas vezes preconceituosas. Páginas na internet também se apropriam do webnamoro para ofertas de serviços relacionados aos videogames. Estamos inseridos em uma hiper-realidade com a indefinição da linha entre o ficcional e o real.

Os personagens de videogames se apresentam como uma folha em branco, sendo preenchidos com as projeções dos jogadores que reverberam em suas realidades. Para Han (2017) a libido na sociedade atual é investida principalmente na própria subjetividade. E nessa busca por afeto, os cosplayers são apresentados como a corporalidade dos personagens de videogames. Esses que despertam interesses amorosos em uma nova geração de jogadores de videogames. A entrevista com Lola Waifu mostrou como existe um mercado consumidor que busca afeto, sexo e carinho através de acompanhantes/cosplayers. Que mesmo não se estendendo efetivamente para o mundo real, se potencializa e se reverbera no cotidiano regular online, ainda mais em tempos de pandemia, onde a plataformização da vida em movimentos migratórios fomentam a hiper-realidade.

Nesse sentido, percebemos o videogame como uma tecnologia da imagem e do imaginário. Afinal, trata-se de uma interface comunicacional dotada de mobilizar seus usuários afetivamente, capaz de reverberar em seus cotidianos desejos e anseios. $O$ transporte da performance comunicativa do digital para o real. Os games como uma ponte pra o preenchimento de uma busca pelo outro e consequentemente a reafirmação de suas crenças e realidade, evidenciam uma forma de expressão cultural da nossa atualidade digital. Essa condição se torna mais evidente durante a atual pandemia causada pela Covid-19. Essa constante pode ser, diante dos apurados ao longo do artigo, considerada também uma usina criativa incessante do imaginário digital da espécie humana. Esta, a cada input/output por onde a comunicação performa, lança no mundo invenções e práticas como uma fogueira libera fagulhas no espaço (DUARTE; CIRINO, 2017). O webnamorados(as) e as 
acompanhantes alugadas são páginas em branco destinadas a preencher o vazio do consumidor através de uma prestação de serviço.

Antes da pandemia de Covid-19 já existia o crescente interesse por uma relação afetiva entre os jogadores e personagens de videogames. Essa relação que transborda para a prática do cosplay. Em ambos os cenários se percebe que o sistema capitalista se apropria desses desejos ao oferecer serviços de webnamoro e sexuais. Acreditamos que isso é um caminho sem volta, e nos próximos anos observaremos uma crescente e cada vez mais explícita relação entre afeto, sexualidade e videogames. Nos resta questionar como será o choque geracional entre os nativos digitais em busca de novos meios de afeto, e as gerações anteriores.

\section{Referências}

ASCOTT, R. Quando a Onça se Deita com a Ovelha: a Arte com Mídias Úmidas e a Cultura Pósbiológica. In: DOMINGUES, D. (Org.). Arte e Vida no Século XXI - Tecnologia, Ciência e Criatividade. São Paulo: Editora Unesp, 2003, pp. 273-284.

BAUDRILLARD, J. Ballard/"Crash"/Baudrillard. Science Fiction Studies, vol. 19, n. 3, 1992.

BAUDRILLARD, J. Simulacros e Simulação. Lisboa: Relógio D’Água, 1991.

BURNS, M. The King and his Objects. Magical Wasteland 2014. Disponível em: $<$ https://www.magicalwasteland.com/notes/2014/8/22/the-king-and-his-objects $>$. Acesso em: 15 set. 2020 .

DERY, M. Velocidade de escape: cibercultura no fim do século. Coimbra: Editora Quarteto, 2000.

DUARTE, E.; CIRINO, N. A imagem além do tempo: a construção do imaginário do futuro nos produtos midiáticos. Intexto, vol. 40, 2017.

DUARTE, M. A arte como experiência (resenha de DEWEY, J. Art as Experience). Crítica Cultural, vol. 12, n. 1, 2017.

FORTIM, I.; PIRRO, R. A mulher como jogadora e consumidora de jogos digitais: Pesquisa Game Brasil 2017. In: BLANCO, B.; GOULART, L. (Org.). Videogames, Diversidade e Gênero: Pesquisa Científica e Acadêmica. São Paulo: Oficina Lúdica, 2019.

FRANCO, E. Arte, Tecnologia, Estética e Ética. Revista Metodista, vol. 13, n. 22, 2010.

GIDDENS, A. A transformação da intimidade: sexualixade, amor e erotismo nas sociedades modernas. São Paulo: Editora UNESP, 1992.

HAN, B. C. Agonia do Eros. Petrópolis: Editora Vozes, 2017.

HAN, B. C. Sociedade do Cansaço. Petrópolis: Editora Vozes, 2015.

JOBIM E SOUZA, S.; GAMBA JR. N. Novos suportes, antigos temores: tecnologia e confronto de gerações nas práticas de leitura e escrita. Revista Brasileira de Educação, vol. 21, 2002.

KNOWYOURMEME. Ahegao - Etymology \& History. Disponível em: $<$ https://knowyourmeme.com/memes/subcultures/ahegao $>$. Acesso em: 15 set. 2020.

LOLA WAIFU. Entrevista com Lola Waifu [WhatsApp]. Lola Waifu: A musa da hiper-realidade. Concedida a José Antônio Loures, 2020.

LOURES, J. Fantasias digitais: Os MODs sexuais para videogames. Em: Anais do \#16.ART Encontro Internacional de Arte e Tecnologia. 2017.

LOURES, J. Homo sex ludes: a sexualidade nos videogames. Tese (Doutorado em Artes Visuais) UnB, Brasília, 2020. 
MARTINS, V. [ENTRE]MUNDOS: Uma narrativa ficcional transmídia. Dissertação (Mestrado em Arte e Cultura Visual) - UFG, Goiânia, 2015.

MATURANA, H. Cognição, ciência e vida cotidiana. Belo Horizonte: Editora UFMG, 2001.

MORAES, E.; LAPEIZ, S. O que é pornografia. São Paulo: Editora Brasiliense, 1985.

MURRAY, J. Hamlet no Holodeck: O futuro da narrativa no ciberespaço. São Paulo: Itáu Cultural, 2003.

NUNES, M. A Cena Cosplay: vinculações e produção de subjetividade. Revista Famecos, vol. 20, n. $2,2013$.

NUNES, M. R. F. (Org.). Cena Cosplay: comunicação, consumo, memória nas culturas juvenis. Editora Sulina. Porto Alegre, 2015.

PUAR, J. The right to main: debility, capacity, disability. Duke University Press, 2017.

SHAW, A. Gaming at the Edge: Sexuality and Gender at the Margins of Gamer Culture. Londres: University of Minnesota Press, 2014.

SIOUX; BLEND; ESPM. Pesquisa Game Brasil 2020. 2020.

VAN DJICK, J.; POELL, T.; WAAL, M. The platform society: public values in a connected world. [s. 1: s. n.], 2018. 